\title{
The Effect of Fear of Failure on Confidence in, and Comfortableness With, the Delivery of End-of-life Care
}

John Latham ( $\sim$ johnlatham.dr@gmail.com)

University of Liverpool

Sarah Butchard

University of Liverpool

Stephen Mason

University of Liverpool

\section{Research Article}

Keywords: Physician, doctor, nurse, end of life, palliative, fear of failure, self-efficacy, psychology, medical education

Posted Date: March 7th, 2022

DOI: https://doi.org/10.21203/rs.3.rs-1381292/v1

License: (c) (1) This work is licensed under a Creative Commons Attribution 4.0 International License. Read Full License 


\section{Abstract}

\section{Objective}

To investigate whether fear of failure (FOF) influences a clinician's perception of their confidence and comfortableness with the delivery of end of life (EOL) care, controlling for gender, role, years of experience, and number of EOL conversations.

\section{Design}

Cross-sectional questionnaire study.

\section{Setting}

Two large NHS hospital trusts in the UK, and national UK professional networks.

\section{Participants}

105 doctors and 104 specialist nurses across 20 hospital specialities.

\section{Main outcome measures}

The Performance Failure Appraisal Inventory, the Self-Efficacy in Palliative Care scale, the Thanatophobia Scale.

\section{Analysis}

A two-step multiple regression.

\section{Results}

The study validated the use of the PFAl and its subscales within a novel population group of medical professionals. No. of EOL conversations, gender, and role impacted confidence and comfortableness with EOL care. Fearing loss of interest negatively impacted a clinician's confidence in communicating with patients. Fear of devaluing one's self-estimate negatively impacted confidence in decision making, working with others, and total self-efficacy.

\section{Conclusion}

Three aspects of FOF negatively impacted both doctors and nurses delivery of EOL care.

\section{Practical Implications}

Further study should look at how FOF develops, sustaining factors, and other areas of clinical practice that FOF impacts, drawing also from FOF research outside the field of medicine. Techniques developed to manage FOF in other populations can now be investigated with a medical population.

\section{Introduction}

Care at the end-of-life (EOL) is considered one of the most difficult aspects of medical practice [1]. Guidelines provide clinicians with recommendations for how to offer the most effective EOL care [2,3] and training in EOL care is now integrated into all undergraduate training for Doctors [4] and Nurses [5]. These guidelines and stipulations within the curricula from professional bodies reinforce that good care at the EOL is the responsibility of all HCPs, and within this prognostic disclosure should aim to be comprehensive, timely, and included regularly in conversations with the patient to ensure high quality care [6]

Adhering to these recommendations has been shown to benefit both patients' and clinical staff's experiences of EOL processes and treatment. It helps to establish clear expectations, emphasise the importance of planning and preparing oneself and family, reducing travel and treatment costs for patients and medical professionals / services, and enables a more effective grief and bereavement process for family and medical teams alike [7-9]. In a study of cancer patients, realistic discussions of prognosis, paired with early palliative care, decreased the overuse of unnecessary interventions and, perhaps counterintuitively, prolonged patient survival $[10,11]$.

\subsection{Barriers to effective end-of-life care}

Despite the effectiveness of these recommendations, there appear to be several barriers to implementing them in everyday practice [12,13]. Contrary to evidence-based guidance, medical teams may present patients with prognostic uncertainty under the guise of sparing patients from distress. For example, a study of 1193 patients with incurable metastatic lung or colorectal cancer demonstrated that $74 \%$ of patients believed that chemotherapy could cure their cancer, with a clear indication that obscure patient messaging led to these unhelpful beliefs, and a more traumatic experience at the EOL [14].

Several personality characteristics have been presented to explain the barriers to effective EOL conversations, including healthcare staff heroism [15], paternal control [16, 17], and apathy [18]. Contextual factors have also been identified, including the impact of cultural taboo [19], challenges with patient comprehension [20] or competing demands on time and energy [21].

Numerous psychological factors have also been identified. Fear of uncertainty [22], decision regret [23], a sense of expectation on oneself and others and the resulting fear of failure [24], death anxiety and the reminders of the mortality of self, friends or family [21], and protecting oneself from the experience of grief 
[16] have all been linked with avoidance of effective EOL communication in qualitive interviews with doctors in acute settings.

Of the identified psychological factors, to our knowledge, only one psychological construct has been empirically investigated. Death anxiety, a reminder of one's own mortality and vulnerability to death, and the impact this may have on sharing in someone else's EOL experience [25], has been shown to impact a clinician's empathy, style of communication, the level of detail within communication, and clinical decision-making [26-28]. However, the most recently published systematic review investigating this construct has been unable to find collective evidence to suggest that death anxiety is substantially responsible for limiting the application of taught skills and the implementation of guidance, and triggering avoidance of EOL conversations and care [12], indicating other factors may play a role in this phenomenon.

Psychological factors remain the most likely cause of ineffective or avoided EOL care. Stress, threat, and anxiety have been shown to reduce capacity for frontal cortex activity, the means for processing emotions and building relationships, allowing for practical tasks to take priority and reducing the ability to hold more challenge, complex, and emotionally laden conversations [20,29]. Fear has been found to limit one's ability to intake information and reduce learning and revision capacity, as well as increase sensitivity to the perceived threat [30]. It has been found to negatively impact an individual's ability to empathise, due to a focus on their own survival and self-protection, with a difficulty in dividing their attention to include others [31]. Bearing witness to death is well known to have several psychological impacts on functioning and wellbeing. It can evoke feelings of fear, anxiety, sadness, grief, fatigue, rumination on risk, vulnerability, injustice, helplessness and powerlessness [32-34], with many of these found in medical populations despite regular exposure [35].

Within the medical population, death is considered by some as professional failure, a loss of credibility, and the anticipation of the death of a patient can be seen as a prediction of the event, often resulting in a loss of motivation [36]. A relationship has been demonstrated between physicians feeling powerless in the face of death and reported avoidance behaviours [35, 37]. Kent, Anderson [38] found that negative factors, including perceptions of inadequacy, unpreparedness, and self-criticism, limited the ability to learn from experiences and feel a sense of reward following intervention. However, clinical settings that are more familiar and prepared for death often see positive effects in terms of clinicians' approaches to care and their attitudes towards patients. This then has a bidirectional impact on the wellbeing of those receiving care, and their own anxiety response to death [39].

Within the medical population, death is considered by some as professional failure, a loss of credibility, and the anticipation of the death of a patient can be seen as a prediction of the event, often resulting in a loss of motivation [20]. A relationship has been demonstrated between physicians feeling powerless in the face of death and reported avoidance behaviours [35, 37]. Kent, Anderson, and Owens [38] found that negative factors, including perceptions of inadequacy, unpreparedness, and self-criticism, limited the ability to learn from experiences and feel a sense of reward following intervention. However, clinical settings that are more familiar and prepared for death often see positive effects in terms of clinicians' approaches to care and their attitudes towards patients. This then has a bidirectional impact on the wellbeing of those receiving care, and their own anxiety response to death [39].

Outside of clinical settings, namely in education, business, and sports performance, the impact of fear, namely fear of failure (FOF), as a barrier to performance has been widely researched [40-42]. However, empirical research is yet to explicitly investigate the role FOF plays in the delivery of EOL care in acute medical settings. What is known is that clinical staff who perceive a patient's death as a personal defeat have been found to hold on to grief, avoid further experiences of death, and categorise death as 'bad' [43,44]. Further, medical teams where treatment is not primarily orientated towards EOL prognosis and care, or where the focus of the team is to reduce the likelihood of death, feel the impact of a patient's death more acutely and personally [36].

Understanding the psychological constructs underpinning reluctance to deliver effective care is important for the development of teaching and learning within clinical professionals, ultimately leading to interventions that could offset avoidance in medical treatment and enhance effective care.

\subsection{Fear of failure: A theoretical context}

Fear of failure (FOF) was initially defined as one's attempt to avoid feelings of shame or humiliation as a consequence of being unable to achieve a goal [45]. The definition has been developed into a more cognitive-specific construct by Conroy [46], as a cognitive protective response to the anticipation of a threat to one's ability or sense of worth, with the goal of avoiding any strong or difficult emotional reaction connected to the threat. Within clinical environments, FOF can lead medical professionals to develop strategies that further enable avoidance; this may include aiming to avoid certain specialisms that may induce threat or panic [20,47], even when this conflicts with their core values and hampers essential skill acquisition [15, 29, 48] - a consistent theme across FOF research. Feelings of failure are elicited in clinicians when patients reject treatment, when negotiations fail, or when a patient's body no longer responds to treatment. Failure has been found to be shaped by social and cultural expectations of responsibility; coming both from clinician, peers in medical teams, and patients receiving support $[16,24,36,50-52]$. There may be a cyclical effect with FOF in healthcare settings; avoiding patient deaths and EOL discourse may further impede confidence and comfortableness within this area. Moreover, those who have more experience of patient deaths within specialisms that do not consider death a failure of treatment may also have a lower personal sense of fear about failure [53].

In contexts outside of medicine, for example in business, sport and education, where evaluation is considered fundamental to achievement, high FOF can be perceived to negatively influence physical capacity to endure stress, increase poor coping behaviours like eating disorders and drug abuse, and heighten negative psychological qualities, such as worry, depression, perfectionism and antisocial behaviour [54]. These negative physical and psychological qualities extended beyond sporting performance to the individual's sense of wellbeing and functioning. In these disciplines, tools have been developed to influence failure cognitions, and develop greater opportunity for successful practice [55].

Given EOL care can be characterised by effective communication and intervention, understanding this field may lead to greater experiences of care and wellbeing for patients in the last days and hours of life, and better outcomes for staff members involved in this care. Further, reducing stigma and perception of failure may also generate more open discussion about mistakes, hence facilitating a more honest and open environment in healthcare and education settings.

\subsection{The current study}


This research study aimed to investigate the role of fear and anxiety in EOL care, namely whether FOF influences a clinician's perception of their confidence and comfortableness with the delivery of EOL care. Furthermore, it also explores whether those who are more likely to encounter death in their workplace showed less FOF. It was recognised that other factors may affect EOL conversations, including role, gender, years of experience, and number of EOL conversations, so these covariates have been included in the analysis. The hypothesis was that individuals who score higher on the Performance Failure Appraisal Inventory (IV; PFAI) [56] will show less confidence in how they communicate (DV1), less confidence in making decisions about death experiences (DV2), and less confidence in involving others in decisions (DV3), and will show higher levels of discomfort when working with people who are dying (DV4).

\section{Materials And Method}

\subsection{Study sample and setting}

This study took a cross-sectional quantitive design approach, using a homogenous stratified sample. The stratum subset was doctors and nurses, randomly selected through the distribution of a questionnaire to hospital teams. In this sense it was participant-led distribution.

Sample size was powered on the more conservative test (a medium effect size of $f=0.15$, alpha level $=0.05$ and Power $=0.95$, sample size $=89$ ) calculated using GPower [57] based on the effect sizes found in a comparative study examining the relationship between perfectionism and FOF in athletes ( $f^{2}=$ between 0.27-0.47) [58]. Power was set to 0.95 to account for the need to run four regressions for each of the four dependant variables identified. Further exploratory analysis was accounted for by post-hoc power analysis.

\subsection{Recruitment}

An online anonymous questionnaire was distributed to doctors and nurses who had delivered EOL communication to patients in a trust in a major city in the North West of England, and a trust in the North East of England. A Covid-19 pandemic adaption to the research was to include other local and national networks known to the primary researcher. The distribution was supported by staff within the palliative, psychology, and R\&D teams within each of the two main hospital trusts who sent the link to the questionnaire out to hospital teams and managers, as well as through doctor and nurse online networks. A Freedom of Information request was made to each hospital to identify hospital data on teams / specialisms working in areas with a high prevalence of patient death, and this guided the distribution in the first instance. To encourage participation, $£ 5$ vouchers for an online retailer were offered to the first 85 participants, with funding for the vouchers provided by the lead authors academic department.

The lead researcher requested invitation to speak at these specialist team meetings and following this the team leaders were emailed an anonymous link to send to their teams to complete the study if they wish, within their own time. Follow up emails were sent to teams by the palliative care teams, and the trust R\&D teams.

Although the focus of many comparative studies of EOL treatment has been on physicians, due to their ultimate decision-making responsibility within care proceedings, specialist nurses (defined as nurses working at band 6 and above) have been included in this study as they offer a broader level of care, which may encompass emotional support as well as additional decision-making responsibility [59]. Therefore, nursing management in both trusts were involved also in the distribution and follow up requests.

The study was opened at the start of March 2021. The study closed in July 2021.

\subsection{Inclusion criteria}

- Doctors and specialist nurses who have worked with adult EOL patients.

- Those who have access to a computer or smartphone.

- Location: The two specified north NHS trusts, or other local and national networks.

\subsection{Exclusion criteria}

- Individuals who have not had an EOL conversation with a patient in their care.

- Clinicians working exclusively with children.

- Clinical staff who offer care support but who do not communicate information about EOL prognosis or who are not able to make autonomous decisions about patient treatment. Decision to include only band 6 nurses or above as a result.

\subsection{Ethical considerations}

Before the start of the study, approval was sought from the DClinPsychol Research Committee, within the Department of Clinical Psychology, University of Liverpool, the sponsorship review panel within the University of Liverpool (sponsor ref: UoL001588), the relevant NHS HRA review board (IRAS ref: 289310), and the R\&D departments in each partner trust (North West ref: SP0564; North East ref: 289310). All methods were performed in accordance with the relevant guidelines and regulations. Consent from participants was recorded online and held in a secure database.

Information about participation and the nature of the research was accessible online, at the start of each questionnaire, and participants were required to confirm they understood the objectives of this research, the inclusion and exclusion criteria, their rights as participants, the voluntary nature of the study and the confidentiality of answers and data management before they were able to complete the study. 
No person specific identifiable data was captured and downloaded within the study. Participants were offered a £5 Amazon voucher in exchange for completing the survey. This aspect required the collection of participants' email addresses, but this information was held on a separate database that was only accessible at the end of the study, when the vouchers were distributed. No further expenses were offered to participants or facilitators of the study.

\subsection{Procedure}

Participants were asked to read an information sheet which outlined the objectives of the research, the inclusion and exclusion criteria, their rights as participants, the voluntary nature of the study and the confidentiality of answers and data management. Following this, they were provided with a link to a Qualtrics online questionnaire designed by the researcher. Participants were asked to provide their consent and anonymously complete demographics information (including NHS trust, gender, role, area of specialism, years of experience, and a guestimate frequency of how many EOL conversations they have had per month) and complete three standardised self-report questionnaires.

\subsection{Measures}

The questionnaire contained three elements: the Self-Efficacy in Palliative Care scale (SEPC; as adapted by Mason \& Ellershaw (2004) [60], the Thanatophobia Scale (TS) [61], and The Performance Failure Appraisal Inventory (PFAI) [56].

Confidence with EOL care: Measured using the Self-Efficacy in Palliative Care scale [60], which assesses efficacy in communication, patient management and multi-professional teamworking. The SEPC has 23 items, measured on a Visual Analogue scale from 'Very anxious' to 'Very competent' over 100 units (0-100). Participants are asked to make a mark on a line between these two points to indicate their selection.

Comfortableness with EOL care: Measured using the Thanatophobia Scale [61], which assesses attitudes towards palliative care. The TS is a seven-point ordinal scale containing seven items, including response options of 1 (strongly disagree) to 7 (strongly agree).

The SEPC scale and TS have been shown to be valid and reliable assessment scales within clinical staff populations, with Cronbach's alpha ranges of $0.84-$ 0.85 and $0.92-0.95$ respectively [60].

Within this study, the SEPC and TS questionnaires each began with the statement: 'Presented are a series of statements that relate to issues and experiences that may be encountered when working with someone in the end stages of life. When answering the questions, we would like you to imagine how you think you would feel in relation to the issues and situations presented.'

Fear of Failure: The Performance Failure Appraisal Inventory [PFAl; 56] is a Multidimensional Measure of FOF developed from a meta-theory of emotions, examining FOF as a function of person-environment interaction, rather than a trait or state or global experience. It comprises 25 items that measure five dimensions of threat appraisals associated with FOF: (1) fear of shame and embarrassment (FSE); (2) fear of devaluing one's self-estimate (FDSE); (3) fear of having an uncertain future (FUF); (4) fear of important others losing interest (FIOLI); and (5) fear of upsetting important others (FUIO). The measure uses a five-point scale with response options of -2 ('do not believe it at all'), 0 ('believe it $50 \%$ of the time'), and +2 ('believe it $100 \%$ of the time'). Within this study, all items are introduced with the phrase 'In my medical practice...'.

Although the PFAl has been designed for use in North American Sports populations, it has been validated in different languages and contexts. It has not, however, been validated within medical settings. Contact with the author of the measure confirmed that it should be suitable for use within this context as it is designed to assess a broad motivational disposition rather than context-specific motivation. Given that this is the first application of the measure in this context, very little is known about the psychometric properties of scores on this measure in healthcare populations. Therefore, although not part of the primary research question of this paper, the internal consistency of the PFAl has been examined to ensure reliability and how the items represent the full construct of PFAl, with the aim to create a platform for others to develop the use of the measure in the future. Given the recent problems uncovered with Cronbach's alpha, especially with small samples and potential non-normality [62], both Cronbach's alpha and McDonald's $\omega$ will be presented.

\subsection{Data analysis}

To test the hypothesis that people who score higher on the PFAl will show less confidence in how they communicate (DV1), make decisions (DV2) and work with others (DV3), and show higher levels of discomfort (DV4), a hierarchical regression was applied. Covariates were included in step 1 (gender, role, area of specialism, years of experience, and a frequency guestimate of how many EOL conversations had per month). Step 2 tested the potential relationships between FOF, as measured by the PFAl total score, and each dependant variable. A further exploratory analysis looked at the subscales of the PFAI measure against each variable, was well as including an additional DV, total SEPC score.

\subsection{Data storage}

Data was recorded, anonymised, and contained within the online Qualtrics platform. The anonymous data was then transferred for formatting using Microsoft Excel, and analysis using Jamovi [63].

\section{Results}

\subsection{Description statistics}

A total of 306 individuals took part in the study. Of these, 203 responses were included for analysis, with the remainder excluded due to not meeting eligibility criteria or submitting incomplete data. 
As can be seen from Table 1, there was almost an equal mix of doctors and nurses in the sample and the majority of responses were from the North West NHS Trust. When compared with workforce numbers accessed through a FOI request for The North West Trust and the North East Trust, $2.8 \%$ of the eligible workforce within the North West Trust and $2.3 \%$ of those in the North East Trust completed the questionnaire, indicating a proportionate representation across the sample.

As Table 1 shows, the total sample was skewed towards female respondents. Across all participants, 82 out of 15 (85\%) of the nursing sample was female, and for doctors 63 (61\%) were male, and 40 (39\%) were female, which is reflective of the gender distribution in the healthcare workforce in the UK, as reported by the Kings Fund (2018).

Table 1

Frequencies of participants by NHS Trust, Role and Gender

\begin{tabular}{|c|c|c|c|c|c|c|c|c|}
\hline \multirow[t]{2}{*}{ NHS Trust } & \multicolumn{5}{|c|}{ Role } & \multicolumn{3}{|c|}{ Gender distribution } \\
\hline & Count & $\%$ of total & & Count & $\%$ of total & Male & Female & Do not wish to disclose \\
\hline \multirow[t]{2}{*}{ North West NHS Trust } & 85 & $41.7 \%$ & Doctor & 43 & $20.98 \%$ & 31 & 12 & 0 \\
\hline & & & Nurse & 42 & $20.5 \%$ & 8 & 35 & 0 \\
\hline \multirow[t]{2}{*}{ North East NHS Trust } & 58 & $28.4 \%$ & Doctor & 29 & $14.1 \%$ & 17 & 11 & 1 \\
\hline & & & Nurse & 29 & $14.1 \%$ & 5 & 24 & 0 \\
\hline \multirow[t]{2}{*}{ Other NHS Trust } & 61 & $29.9 \%$ & Doctor & 32 & $15.6 \%$ & 15 & 17 & 0 \\
\hline & & & Nurse & 29 & $14.1 \%$ & 2 & 26 & 1 \\
\hline \multirow[t]{2}{*}{ Overall Total: } & 205 & & Doctors & 104 & $50.7 \%$ & $78(38 \%)$ & $125(61 \%)$ & $2(0.97 \%)$ \\
\hline & & & Nurses & 101 & $49.3 \%$ & & & \\
\hline
\end{tabular}

Figure 1 shows that most respondents from the North West NHS Trust had between $5-10$ years' experience $(n=31,36 \%)$, followed by $3-5$ and $10-15$ years (n $=14,16 \%$ for each category). In the North East NHS Trust the results were more evenly spread across the sample, with the majority having $10-15$ years' experience $(n=14,24 \%)$ followed by $5-10$ years $(n=13,22 \%)$, and $15-30$ years $(n=10,17 \%)$. Responses from local and national networks outside of these trusts had much less experience comparatively, with the majority having $1-3$ years' experience $(n=17,28 \%)$, followed by $3-5$ years $(n=11,18 \%)$ and $5-10$ years $(n=10,16 \%)$. There was no significant gender difference in the number of years of experience reported $(U=4873, p=0.996)$.

When looking at how years of experience relates to EOL conversations per month, in general the more years of experience the more EOL conversations had. The most frequently reported number of EOL conversations for people with between $0-3$ years' experience was between 1-2 conversations per month. People with between 3-15 years' experience most frequently reported 2-5 conversations per month. This figure jumps to more than 12 conversations per month for people with between 15-30 years of experience but reduces again for those with $30+$ years' experience, who reported 1-3 conversations per month.

Participants were asked about their areas of specialism to give an indication of sample and response rate distribution across hospital specialism areas (Table 2). Fifteen percent of participants $(n=30)$ did not state their clinical speciality. The speciality groups with the biggest response rate included Oncology $(n=26,12.7 \%)$, Cardiovascular medicine $(n=25,12.2 \%)$, and Palliative medicine $(n=21,10.2 \%)$. Although these groups were targeted for distribution due to their high ward death rates in FOI requests, which may explain a greater response rate than some other clinical specialities, other targeted specialities did not show the same level of response, including Geriatric medicine $(n=11,5.4 \%)$ Endocrinology $(n=1,0.5 \%)$ and Haematology $(n=13,6.3 \%)$.

\subsection{Differences between groups}

Given that the data was not normally distributed, a non-parametric test was used to look at the relationship between gender and the scores on the PFAl, SEPC and TS, excluding the results of the two participants who did not report a binary gender. A Mann-Whitney U test (Fig. 2) showed that there was not a significant effect for gender on the PFAI nor the Self-Efficacy scale (SEPC) total score or subdomain scores. There was however a significant effect for gender $(U=3057$, $p=<.001)$ on the Thanatophobia scale (comfortableness with death) with male respondents feeling less comfortable with death $(M=24.6, S D=9.78)$ compared to female responses $(M=18.2, S D=9.26$; Fig. 3). Cohen's effect size value $(d=.37)$ indicates a moderate to large practical significance.

There was no significant difference between doctors and nurses scores on the FOF and Self-Efficacy measures, but a difference was found on the Thanatophobia scale $(U=3579, p=<.001)$, with doctors reporting higher levels of discomfort with death $(M=23.29, S D=9.76)$ than nurses $(M=17.99, S D=$ 9.31; Fig. 3). Cohen's effect size value $(d=.56)$ indicates a large practical significance.

\subsection{Internal consistency reliability analysis}

The PFAl subscales consisted of 25 items and were found to be highly consistent across all items $(a=0.920 ; \omega=0.921)$, indicating it is an effective measure when measuring medical populations. The strength of relationship between subscales of the PFAl is shown in Fig. 4 .

\subsection{Multiple Linear Regression}

\subsubsection{Planned analysis}


To approach the question of whether an increase in clinicians scoring higher on the PFAl associated with a change in confidence in how a clinician communicates (DV1), makes decisions (DV2), works with others (DV3), and comfortableness about providing EOL care (DV4), a two-step hierarchical linear regression was conducted (Table 3).

For the first hierarchical linear regression analysis looking at confidence in clinician communication (DV1), step 1 included the covariates gender, role, years of experience, and number of EOL conversations per month. The results of this revealed a model that was a good fit to the data. This step accounted for $8.2 \%$ of the variation in confidence in clinician communication with patients at the EOL. Estimated number of EOL conversations per month was the significant factor within this model, meaning people who had more conversations were more confident in their communication. For the second step, PFAl total score was included as a measure of FOF, controlling for the four previous covariates. The model was a good fit for the data and accounted for $-0.4 \%$ of the variance in confidence in EOL conversations. However, the regression coefficient for FOF was not significant, indicating no significant relationship could be found. This process was repeated for each additional dependent variable.

For DV2, confidence in clinician decision making, results revealed a model that was a good fit to the data. The first step accounted for $8.8 \%$ of the variation in confidence with decision making with patients at the EOL. Estimated number of EOL conversations per month was the only significant factor within this model, meaning people who had more EOL conversations were more confident in their decision making. For the second step, the model was a good fit for the data and accounted for $-0.26 \%$ of the variance in confidence in EOL conversations. However, the regression coefficient for FOF was not significant.

For DV3, confidence in working with others, neither model was shown to be a good fit to the data.

For DV4, a clinician's comfortableness about providing EOL care, results revealed a model that was a good fit to the data. This step accounted for $11.6 \%$ of the variation in a clinician's comfortableness with death. Gender, role, and estimated number of EOL conversations per month were the three significant factors within this model, with men less comfortable with death than women, and doctors less comfortable than nurses. Once again, people who had more conversations per month were less uncomfortable with EOL work. For the second step, FOF was included, controlling for the four previous covariates. The model was a good fit for the data and accounted for $-0.3 \%$ of the variance in comfortableness with death. However, the regression coefficient was not significant. 
Table 3

Regression analysis showing Gender, Role, Years of experience, Number of EOL conversations, and FOF score as predictors of each dependent variable, to thrt decimal places

\begin{tabular}{|c|c|c|c|c|c|c|c|c|c|c|c|c|c|}
\hline \multirow{4}{*}{$\begin{array}{l}\text { Dependent } \\
\text { Variable }\end{array}$} & \multirow{4}{*}{ Variable } & \multicolumn{6}{|l|}{ Step 1} & \multicolumn{6}{|l|}{ Step 2} \\
\hline & & \multicolumn{2}{|c|}{ Cumulative } & \multicolumn{4}{|c|}{ Simultaneous } & \multicolumn{2}{|c|}{ Cumulative } & \multicolumn{4}{|c|}{ Simultaneous } \\
\hline & & \multirow{2}{*}{$\begin{array}{l}\text { Adjusted } \\
\mathrm{R}^{2}\end{array}$} & \multirow{2}{*}{$\begin{array}{l}\text { Model } \\
\text { Fit }\end{array}$} & \multirow[t]{2}{*}{$\beta$} & \multicolumn{2}{|c|}{ 95\% C.I. } & \multirow[t]{2}{*}{$\mathrm{p}$} & \multirow{2}{*}{$\begin{array}{l}\text { Adjusted } \\
\mathrm{R}^{2}\end{array}$} & \multirow{2}{*}{$\begin{array}{l}\text { Model } \\
\text { Fit }\end{array}$} & \multirow[t]{2}{*}{$\beta$} & \multicolumn{2}{|c|}{ 95\% C.I. } & \multirow[t]{2}{*}{$\mathrm{p}$} \\
\hline & & & & & Lower & Upper & & & & & Lower & Upper & \\
\hline \multirow{6}{*}{$\begin{array}{l}\text { Communication } \\
\text { (DV1) }\end{array}$} & & \multirow[t]{5}{*}{0.082} & \multirow{5}{*}{$\begin{array}{l}\mathrm{F} \\
(4,198) \\
=5.53 \\
\mathrm{p} \\
<.001\end{array}$} & & & & & & & & & & \\
\hline & Gender & & & 3.585 & -3.96 & 11.14 & 0.350 & & & 3.587 & -3.98 & 11.16 & 0.35 \\
\hline & Role & & & 2.072 & -5.37 & 9.51 & 0.583 & & & 2.130 & -5.35 & 9.61 & 0.57 \\
\hline & $\begin{array}{l}\text { Years of } \\
\text { experience }\end{array}$ & & & 0.510 & -1.56 & 2.58 & 0.628 & & & 0.537 & -1.56 & 2.63 & 0.61 \\
\hline & $\begin{array}{l}\text { Number of } \\
\text { end-of-life } \\
\text { conversations } \\
\text { per month }\end{array}$ & & & 4.654 & 2.47 & 6.84 & $<.001$ & & & 4.653 & 2.46 & 6.85 & $<.00$ \\
\hline & $\begin{array}{l}\text { Fear of } \\
\text { Failure score } \\
\text { (PFAl) }\end{array}$ & & & & & & & 0.078 & $\begin{array}{l}\mathrm{F} \\
(5,197) \\
=4.41 \\
\mathrm{p} \\
<.001\end{array}$ & 0.399 & -3.69 & 4.49 & 0.84 \\
\hline \multirow{6}{*}{$\begin{array}{l}\text { Decision-making } \\
\text { (DV2) }\end{array}$} & & \multirow[t]{5}{*}{0.088} & \multirow{5}{*}{$\begin{array}{l}F \\
(4,198) \\
=5.87 \\
p \\
<.001\end{array}$} & & & & & & & & & & \\
\hline & Gender & & & 3.025 & -3.73 & 9.78 & 0.378 & & & 3.031 & -3.73 & 9.79 & 0.37 \\
\hline & Role & & & 0.523 & -6.13 & 7.17 & 0.877 & & & 0.701 & -5.98 & 7.38 & 0.83 \\
\hline & $\begin{array}{l}\text { Years of } \\
\text { experience }\end{array}$ & & & -0.845 & -2.70 & 1.01 & 0.369 & & & -0.763 & -2.63 & 1.11 & 0.42 \\
\hline & $\begin{array}{l}\text { Number of } \\
\text { end-of-life } \\
\text { conversations } \\
\text { per month }\end{array}$ & & & 4.625 & 2.67 & 6.58 & $<.001$ & & & 4.624 & 2.67 & 6.58 & $<.00$ \\
\hline & $\begin{array}{l}\text { Fear of } \\
\text { Failure score } \\
\text { (PFAl) }\end{array}$ & & & & & & & 0.0854 & $\begin{array}{l}\mathrm{F} \\
(5,197) \\
=4.77, \\
\mathrm{p} \\
<.001\end{array}$ & 1.226 & -2.43 & 4.88 & 0.50 \\
\hline \multirow{6}{*}{$\begin{array}{l}\text { Working with } \\
\text { others (DV3) }\end{array}$} & & \multirow[t]{5}{*}{0.024} & \multirow{5}{*}{$\begin{array}{l}F \\
(4,198) \\
=2.22, \\
p= \\
0.068\end{array}$} & & & & & & & & & & \\
\hline & Gender & & & 3.233 & -4.129 & 10.59 & 0.388 & & & 3.234 & -4.146 & 10.61 & 0.38 \\
\hline & Role & & & 1.268 & -5.983 & 8.52 & 0.731 & & & 1.301 & -5.991 & 8.59 & 0.72 \\
\hline & $\begin{array}{l}\text { Years of } \\
\text { experience }\end{array}$ & & & -0.481 & -2.499 & 1.54 & 0.639 & & & -0.465 & -2.507 & 1.58 & 0.65 \\
\hline & $\begin{array}{l}\text { Number of } \\
\text { end-of-life } \\
\text { conversations } \\
\text { per month }\end{array}$ & & & 2.951 & 0.819 & 5.08 & 0.007 & & & 2.951 & 0.813 & 5.09 & 0.00 \\
\hline & $\begin{array}{l}\text { Fear of } \\
\text { Failure score } \\
\text { (PFAI) }\end{array}$ & & & & & & & 0.019 & $\begin{array}{l}F \\
(5,197) \\
=1.77, \\
p= \\
0.120\end{array}$ & 0.227 & -3.762 & 4.22 & 0.15 \\
\hline \multirow{5}{*}{$\begin{array}{l}\text { Comfortableness } \\
\text { (DV4) }\end{array}$} & & \multirow[t]{5}{*}{0.116} & F & & & & & & & & & & \\
\hline & Gender & & $=7.65$ & -4.560 & -7.588 & -1.532 & 0.003 & & & -4.558 & -7.593 & -1.523 & 0.00 \\
\hline & Role & & $<.001$ & -3.663 & -6.645 & -0.678 & 0.016 & & & -3.612 & -6.611 & -0.614 & 0.01 \\
\hline & $\begin{array}{l}\text { Years of } \\
\text { experience }\end{array}$ & & & 0.313 & -0.517 & 1.144 & 0.458 & & & 0.337 & -0.503 & 1.176 & 0.43 \\
\hline & $\begin{array}{l}\text { Number of } \\
\text { end-of-life } \\
\text { conversations } \\
\text { per month }\end{array}$ & & & -0.876 & -1.753 & 0.001 & 0.050 & & & -0.876 & -1.755 & 0.003 & 0.05 \\
\hline
\end{tabular}




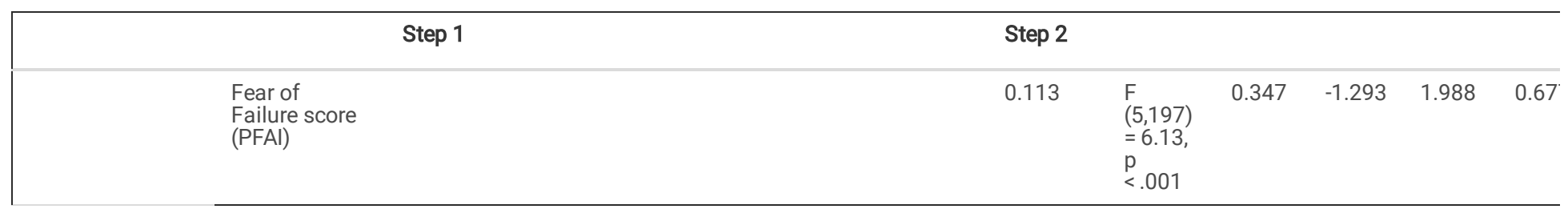

\subsubsection{Exploratory analysis}

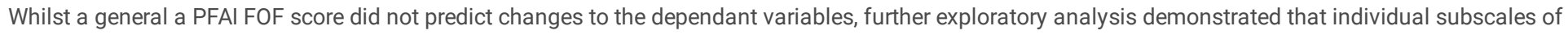

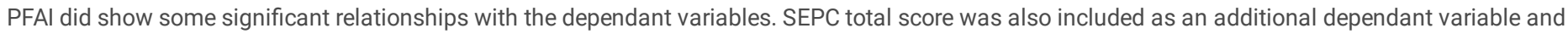
showed a relationship with one of the PFAl subscales (Table 4).

For DV1, when controlling for the four covariates, step 2 of the model was shown to be a good fit for the data and accounted for an additional $9.8 \%$ of the variance in confidence in EOL conversations. Participants who had a greater Fear of Experiencing Shame \& Embarrassment (subscale FSE) had increased confidence in EOL conversations, and those who had greater Fear of Important Others Losing Interest (subscale FIOLI) had lower confidence in EOL conversations. The regression coefficient associated with subscale FSE suggests that as each unit of FSE increases, confidence in communication also increases by approximately 3 units. The regression coefficient associated with subscale FIOLI suggests that as each unit increases, confidence in communication decreases by approximately 7 units.

For DV2, when controlling for the four covariates, step 2 of the model was shown to be a good fit for the data and accounted for an additional $5.8 \%$ of the variance in confidence in EOL decision making. Participants who had a greater Fear of Devaluing One's Self-Estimate (subscale FDSE) had lower confidence in EOL decision making. The regression coefficient associated with this subscale suggests that as each unit of FDSE increases, confidence in decision making decreases by approximately 8 units.

For DV3, step 1 did not reveal a model that was a good fit to the data but step 2 did show a good fit accounting for another $1 \%$ of the variance, but given step 1 was not a good fit this may not be a reliable assessment of variance. Within step 2, Fear of Devaluing One's Self-Estimate (subscale FDSE) had lower confidence in working with others. The regression coefficient associated with this subscale suggests that as each unit of FDSE increases, confidence in decision making decreases by approximately 6 units. For DV4, comfortableness with death and EOL care, results for both step 1 and 2 revealed a model that was a good fit to the data. In step 1, gender, role, and estimated number of EOL conversations per month showed a relationship with comfortableness, which was consistent with earlier results. However, the regression coefficients explored for step 2 were not significant, so no further observations could be made about the impact of the FOF subscales.

For SEPC total, the total score from the self-perceived efficacy in palliative care scale, results revealed a model that was a good fit to the data. This step accounted for $8.2 \%$ of the variation in perceived self-efficacy delivering EOL care. Estimated number of EOL conversations per month was the only significant factor within this model, meaning people who had more conversations were shown to have a higher sense of self-efficacy. For step 2, when controlling for the four covariates, the model was a good fit for the data and accounted for an additional $7.3 \%$ of the variance in self-efficacy. Participants who had a greater Fear of Devaluing One's Self-Estimate (subscale FDSE) had lower confidence in their self-efficacy when delivering EOL care. The regression coefficient associated with this subscale suggests that as each unit of FDSE increases, total self-efficacy decreases by approximately 6 units. 
Table 4

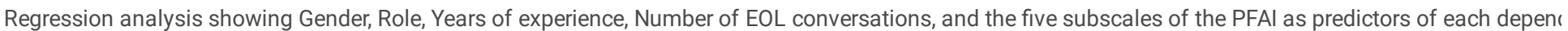
variable, as well as total SEPC score as an exploratory dependant variable, to three d.p.'s

\begin{tabular}{|c|c|c|c|c|c|c|c|c|c|c|c|c|c|}
\hline \multirow{4}{*}{$\begin{array}{l}\text { Dependent } \\
\text { Variable }\end{array}$} & \multirow{4}{*}{ Variable } & \multicolumn{6}{|l|}{ Step 1} & \multicolumn{6}{|c|}{ Step 2 - Individual PFAl factors } \\
\hline & & \multicolumn{2}{|c|}{ Cumulative } & \multicolumn{4}{|c|}{ Simultaneous } & \multicolumn{2}{|c|}{ Cumulative } & \multicolumn{4}{|c|}{ Simultaneous } \\
\hline & & \multirow{2}{*}{$\begin{array}{l}\text { Adjusted } \\
\mathrm{R}^{2}\end{array}$} & \multirow{2}{*}{$\begin{array}{l}\text { Model } \\
\text { Fit }\end{array}$} & \multirow[t]{2}{*}{$\beta$} & \multicolumn{2}{|c|}{ 95\% C.I. } & \multirow[t]{2}{*}{$\mathrm{p}$} & \multirow{2}{*}{$\begin{array}{l}\text { Adjusted } \\
\mathrm{R}^{2}\end{array}$} & \multirow{2}{*}{$\begin{array}{l}\text { Model } \\
\text { Fit }\end{array}$} & \multirow[t]{2}{*}{$\beta$} & \multicolumn{2}{|l|}{ 95\% C.I. } & \multirow[t]{2}{*}{$\mathrm{p}$} \\
\hline & & & & & Lower & Upper & & & & & Lower & Upper & \\
\hline \multirow{10}{*}{$\begin{array}{l}\text { Communication } \\
\text { (DV1) }\end{array}$} & & \multirow[t]{5}{*}{0.083} & \multirow{5}{*}{$\begin{array}{l}F \\
(4,200) \\
=5.63 \\
p \\
<.001\end{array}$} & & & & & & & & & & \\
\hline & Gender & & & 2.960 & -3.600 & 9.520 & 0.375 & & & 0.971 & -5.332 & 7.280 & $0 . \overline{1}$ \\
\hline & Role & & & 2.319 & -4.810 & 9.440 & 0.522 & & & 1.802 & -5.015 & 8.620 & 0.6 \\
\hline & $\begin{array}{l}\text { Years of } \\
\text { experience }\end{array}$ & & & 0.504 & -1.550 & 2.560 & 0.630 & & & 0.406 & -1.555 & 2.370 & $0 . \epsilon$ \\
\hline & $\begin{array}{l}\text { Number of } \\
\text { end-of-life } \\
\text { conversations } \\
\text { per month }\end{array}$ & & & 4.718 & 2.570 & 6.870 & $<.001$ & & & 4.286 & 2.245 & 6.330 & $<$.l \\
\hline & FSE & & & & & & & \multirow[t]{5}{*}{0.181} & & 3.125 & -0.027 & 6.220 & $0 . C$ \\
\hline & FDSE & & & & & & & & $=6.01$, & -3.341 & -8.706 & 2.020 & 0.2 \\
\hline & FUF & & & & & & & & $<.001$ & -0.211 & -5.793 & 5.370 & $0 . c$ \\
\hline & FIOLI & & & & & & & & & -6.735 & $\overline{12.034}$ & -1.440 & $0 . C$ \\
\hline & FUIO & & & & & & & & & 1.250 & -4.605 & 7.110 & $0 . \epsilon$ \\
\hline \multirow{10}{*}{$\begin{array}{l}\text { Decision-making } \\
\text { (DV2) }\end{array}$} & & \multirow[t]{10}{*}{0.089} & \multirow{10}{*}{$\begin{array}{l}F \\
(9,195) \\
=5.98 \\
p \\
<.001\end{array}$} & & & & & & & & & & \\
\hline & Gender & & & 2.443 & -3.420 & 8.310 & 0.412 & & & 0.718 & -5.053 & 6.488 & $0 . \varepsilon$ \\
\hline & Role & & & 0.884 & -5.530 & 7.210 & 0.795 & & & 1.104 & -5.137 & 7.345 & $0 . \overline{1}$ \\
\hline & $\begin{array}{l}\text { Years of } \\
\text { experience }\end{array}$ & & & -0.834 & -2.670 & 1.000 & 0.372 & & & -1.066 & -2.861 & 0.730 & 0.2 \\
\hline & $\begin{array}{l}\text { Number of } \\
\text { end-of-life } \\
\text { conversations } \\
\text { per month }\end{array}$ & & & 4.680 & 2.760 & 6.600 & $<.001$ & & & 4.376 & 2.508 & 6.244 & $<$.1 \\
\hline & FSE & & & & & & & 0.147 & $\mathrm{~F}$ & 2.445 & -0.391 & 5.282 & $0 . C$ \\
\hline & FDSE & & & & & & & & $=4.90$, & -7.887 & -12.799 & -2.976 & $0 . C$ \\
\hline & FUF & & & & & & & & $<.001$ & 1.211 & -3.899 & 6.320 & $0 . \epsilon$ \\
\hline & FIOLI & & & & & & & & & -1.175 & -6.026 & 3.676 & $0 . \epsilon$ \\
\hline & FUIO & & & & & & & & & 2.093 & -3.267 & 7.453 & 0.4 \\
\hline Working with & & 0.025 & F & & & & & & & & & & \\
\hline & Gender & & $=2.28$, & 1.438 & -4.970 & 7.850 & 0.659 & & & 0.272 & -6.133 & 6.676 & $0 . c$ \\
\hline & Role & & $<.062$ & 2.259 & -4.700 & 9.220 & 0.523 & & & 2.173 & -4.754 & 9.100 & 0.5 \\
\hline & $\begin{array}{l}\text { Years of } \\
\text { experience }\end{array}$ & & & -0.445 & -2.450 & 1.560 & 0.663 & & & -0.597 & -2.590 & 1.396 & 0.5 \\
\hline & $\begin{array}{l}\text { Number of } \\
\text { end-of-life } \\
\text { conversations } \\
\text { per month }\end{array}$ & & & 3.120 & 1.020 & 5.220 & 0.004 & & & 2.824 & 0.751 & 4.898 & $0 . C$ \\
\hline & FSE & & & & & & & 0.057 & & 2.062 & -1.086 & 5.211 & 0.1 \\
\hline & FDSE & & & & & & & & $=2.38$, & -5.873 & -11.325 & -0.422 & $0 . C$ \\
\hline & FUF & & & & & & & & $<.014$ & 0.4 .33 & -5.238 & 6.104 & $0 . \varepsilon$ \\
\hline & FIOLI & & & & & & & & & -4.031 & -9.415 & 1.353 & 0.1 \\
\hline & FUIO & & & & & & & & & 5.372 & -0.577 & 11.321 & $0 . C$ \\
\hline $\begin{array}{l}\text { Comfortableness } \\
\text { (DV4) }\end{array}$ & & 0.110 & $\begin{array}{l}F \\
(4,200)\end{array}$ & & & & & & & & & & \\
\hline
\end{tabular}

Page 10/17 


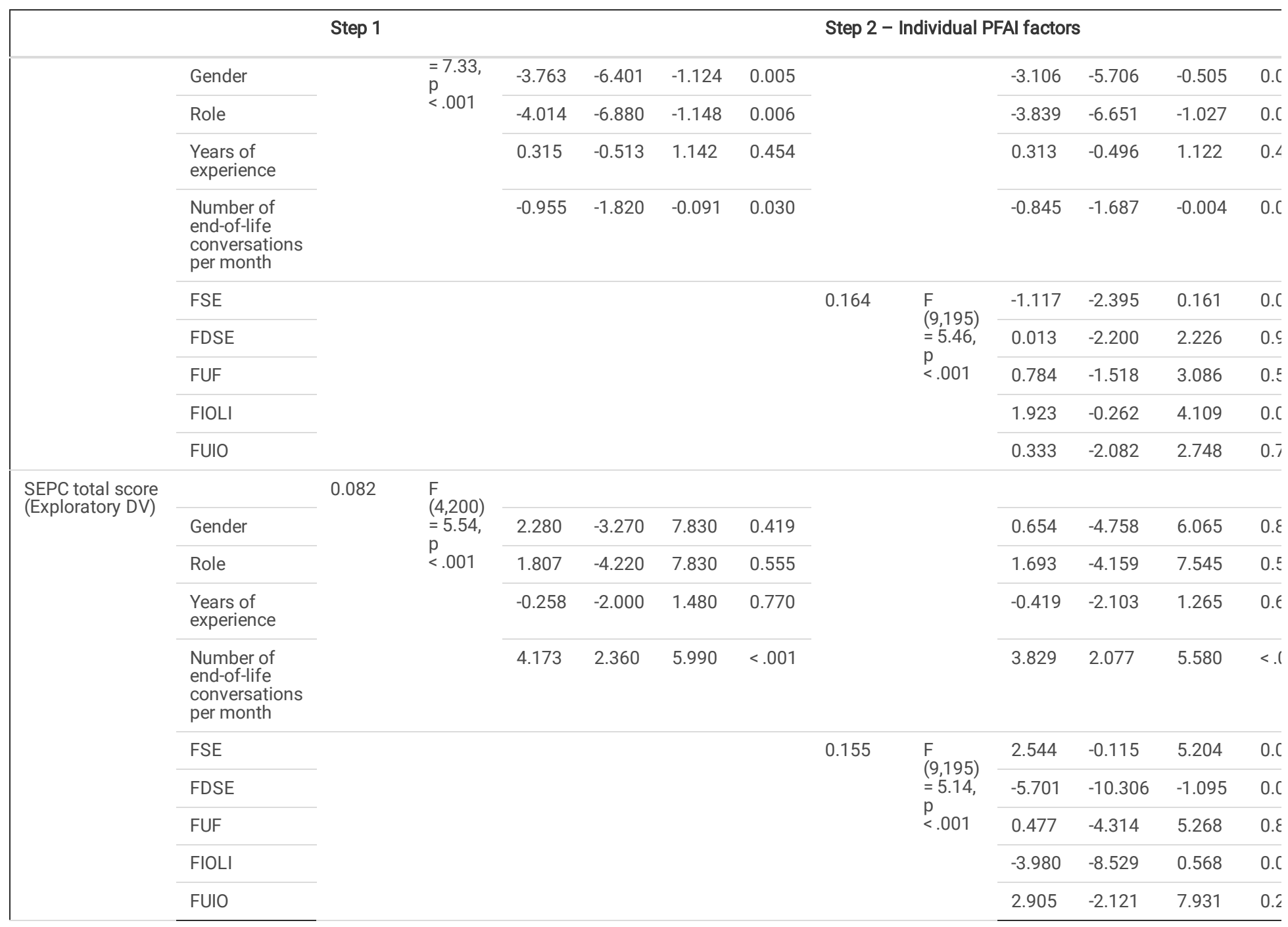

\section{Discussion}

This study has identified that FOF as a general concept, as defined by the PFAl, was not shown to have an impact on a doctors' or nurses' perceived ability to deliver effective EOL care. Contrary to the hypothesis, after controlling for gender, role, years of experience, and number of EOL conversations per month, FOF did not impact confidence in communication, decision making, team working and comfortableness with EOL care. Estimated numbers of EOL conversations per month impacted all four of the variables measured, and gender and role had an additional impact on how comfortable a clinician was with EOL care and death. The study also has validated the use of the PFAl and its subscales within a new population group - medical professionals.

However, further exploratory analysis found that the subscales of the PFAI did show significant relationships with the dependant variables. A clinician who fears the loss of interest in them and their professional opinion was shown to negatively impact a clinician's confidence in communicating with patients. Fears of devaluing one's self-estimate, which looks at self-depreciation, blaming lack of talent or intellect for the situation, and disappointment in self, was found to negatively impact confidence in decision making, working with others, and total self-efficacy. Interestingly, higher scores related to fear of shame or embarrassment increased confidence in communication, which is consistent with shame research suggesting that shame is a short-term motivator, but is linked to long term consequences like lower resilience and low mood [64].

Working with others was impacted by the FOF subscale Fear of Devaluing One's Self-Estimate, which is consistent to the literature suggesting that some professionals are reluctant to engage and work with palliative care teams in the care of their patients due to the fear that this indicates the failure of their treatment [24,52]. Given there were not more relationships shown with other FIF subscales might indicate that the 'working with others' questions on the SEPC scale do not accurately measure a person's likelihood to engage a palliative care team, but rather their confidence if they happen to work with other teams. Further, if a clinician is resistant to accepting that death is approaching, they may not consider a referral to a palliative service appropriate, and therefore it would not be considered a reluctance, but instead related to an inaccurate belief in their ability. It could also relate to therapeutic nihilism, and a belief that another service would be no more effective than current treatment, which has been highlighted most recently in the field of geronto-oncology [65]. There may also be a social bias related to reporting a reluctance to work with others, especially in settings or specialisms that promote or are guided toward MDT working [66].

A further unexpected result was in relation to who has end of life conversations most frequently. Within this study sample relatively few junior staff have end of life conversations, with the overwhelming majority delivered by people with between 15-30 years of experience. Based on the literature reviewed, which 
reported that senior colleagues often ask junior colleagues to have EOL conversations on their behalf [21, 23], that junior doctors feel unsupported, over relied on, and sometimes judged by their senior colleagues [67], and very few saw positive examples of EOL conversations being delivered [3, 16], it would be expected that more junior staff would report having EOL conversations, and fewer senior members of staff would report having EOL conversations. However, this discrepancy with the data presented could be explained by an over estimation by senior clinicians of their engagement with EOL patients or by a reluctance of senior clinicians to be observed by others, perhaps related to fear of criticism if not a fear of failure. The literature may however also simply describe one of the limitations of the hospital environment, in that there are too few clinicians available to meet all the demands of the role as well as to offer shadowing or observation experiences, or that it may not be considered appropriate to have observers present.

There was a higher reported level of discomfort with death in doctors, particularly male clinicians, rather than nurses and female clinicians, but both showed some level of discomfort. Given that many senior clinicians having end of life conversation were male doctors, one could assume that this target group may be less likely to want to encourage observation and peer learning or maybe more impacted by the psychological FOF factors identified in this study.

In line with the literature there may have been some reluctance from some specialities in completing the EOL questionnaire. Haematology has been previously identified as a speciality that 'treats until the end' and engagement with palliative teams results in a sense of 'giving up' [20]. Despite the deliberate push to recruit from these teams, and the primary researcher presenting at several senior team meetings, they were not as responsive as other targeted groups. Other specialities that have very high death rates also were unexpectedly low in terms of response rate. Geriatric medicine and endocrinology are not often identified in literature as specialities that experience reluctance; geriatric medicine reportedly works very closely with palliative care teams given the age of their population [19]. It may be that several factors influence response rates, including the Covid-19 pandemic with stretched healthcare staff with less availability to complete the study and the movement of doctors and nurses into specialities that were not familiar to them to meet demand of the pandemic. The response rate for speciality may also not account for specialities that have smaller teams, rather than a reluctance in these groups to engage. Unfortunately, the FOI request on eligible workforce numbers from trusts did not break the figures down by specialisms, so further analysis to explore this area was not possible.

The data for this study was collected during the Covid-19 pandemic, which was timely given the distressingly high death rates in the UK and globally, and the united effort of clinicians from all disciplines in the management of very unwell patients. Many practitioners unfamiliar or less inclined to engage with EOL processes have been required to utilise these skills, and this may have been one of the factors that positively impacted the rate and enthusiasm of response to this study and the diversity of respondents. It also may demonstrate a current desire from clinicians for opportunities to reflect on their experience of EOL care and the factors influencing confidence, comfortableness, and reluctance.

\subsection{Strengths and Limitations}

As described by Conroy [46] FOF can be viewed as a cognitive protective response to the anticipation of threat to one's ability or sense of worth, the goal of avoiding strong or difficult emotions. These same processes could have impacted the honest reporting of fears of failure, or elements of cognitive dissonance, especially in relation to such a sensitive and often avoided topic and could explain why the general FOF score was unable to produce a significant relationship with the SEPC and TS scales.

Replicating this study but comparing FOF with a less sensitive topic may be helpful in identifying whether this measure is effective in this clinical population. Increasing the number of participants, perhaps limiting the study to a single medical role, may clarify any non-significant results. Using self-report measures may not capture the reality of practice given that both conscious and unconscious social biases influencing responses. Observation studies running alongside self-reports can identify discrepancies in reporting and ensure that these are accounted for in subsequent analyses. In-depth interviews may help illuminate whether cognitive dissonance is indeed a limiting factor in questionnaire studies in this area.

The unexpectedly positive response to this study may indicate the need for space to reflect about EOL processes and the psychological factors that impact them, perhaps created, or propelled, by the pressure on clinicians to support EOL patients during the Covid-19 pandemic. Further development of this project would be to compare the responses captured in this study with a period in the future where the healthcare system is less under pressure from dying patients, and to reflect on the impact of acute periods of death on how EOL processes are perceived. Further, given there may be a cyclical effect where avoidance impedes confidence and comfortableness within this area, targeting specialities that reportedly present a culture of treating an illness up to the end of life, and comparing their response with other specialities may be useful in identifying whether belief in ability to cure shares similarities with avoidance to acknowledge the reality of death.

Wider application of the PFAl to explore the emotional experience of healthcare workers would further validate its application to this population group and help with the reliability of the measure. However, the study clearly identifies that other psychological factors are likely to play a role in reluctance in EOL processes, and concepts like power, hierarchy, and the anticipation of judgement and criticism could be impacting the care of patients at the EOL, and should be explored in further studies.

There are several strategies that exist for managing fear and anxiety that have emerged from FOF studies in other settings, and the exploratory findings of this study indicate that it may be valuable to explore the use of these strategies within medical populations. Avoidance-focused strategies, like forms of mindfulness, have been found to be a positive strategy when EOL rumination is knowingly affecting decision making within the moment, but relies on creating space for post-event processing [28]. Schwartz rounds are an example of spaces in health settings designed for sharing and reflection, that have been found to be effective in reducing shame and acknowledging difficult health situations [68]. Emotion-focused coping strategies like positive-self talk, positive reinterpretation, lowering goals, seeking emotional support, and problem focused strategies, like increasing effort and education to prevent failure, and confronting salient fears, have also been found to be effective strategies [3,69].

\subsection{Practical Implications}


By understanding the factors impacting EOL care more can be done to reduce their negative effects, and consequently positively impact patient care. Further studies building on these findings may wish to look at how to increase familiarity with EOL working for less confident staff, to look at strategies used by those who report less FOF, as well as effective fear-reducing strategies identified in other FOF literature from business, sports, and education research. It is important that support for managing the psychological factors that impact clinical practice isn't limited to medical or nursing students but is also offered to senior staff members who demonstrate good practice on the wards. This study also demonstrates that there remain a number of unknown psychological factors affecting the delivery of EOL and offers a platform for the development of further research in this area.

\subsection{Conclusion}

Overall, this study has shown that fear of failure as a general concept, as measured by the PFAl, is not representative of a single psychological factor impacting clinicians working in EOL care. That said, three of the five subscales of the PFAl measure did represent some of the psychological factors that impacted clinician delivery of EOL care. Despite significance, the models still only accounted for up to $18 \%$ of the data, indicating other variables outside these factors are likely impacting the delivery of EOL care.

We have demonstrated that by understanding FOF in the context of end-of-life care hospitals can improve outcomes for patients. The scale and diversity of the sample, the validation of a new measure to capture clinician emotional experience, and the robust analysis using a two-step multiple linear regression, has demonstrated links between aspects of FOF and barriers clinicians face in confidence related to communication, decision making and comfortableness with EOL process. Given fear of failure is an undeveloped psychological construct within this population, this research opens opportunity for further exploration, including how aspects of FOF develops, sustaining factors, and other areas of clinical practice that FOF impacts. It also creates opportunity to bring several research fields together, including research from business, education, and sport, that have already been developing the research base and exploring the impact of FOF on performance. Techniques that have been developed to impact the negative effects of FOF for other populations can now be researched and potentially applied to this medical population to see whether the same positive effects can be observed.

\section{Declarations}

Consent for publication - All the authors mentioned in the manuscript have agreed for authorship, read and approved the manuscript, and given consent for submission and subsequent publication of the manuscript.

Availability of data and materials - All data analysed for this study are included in this published article as a supplementary information file.

Competing interests - The results/data/figures in this manuscript have not been published elsewhere, nor are they under consideration by another publisher. All of the material is owned by the authors and/or no permissions are required.

Funding - There are no competing financial interests as defined by BMC, or other interests that might be perceived to influence the results and/or discussion reported in this paper.

Authors' contributions - John Latham wrote the main manuscript text. All authors, John Latham, Sarah Butchard, and Stephen Mason, reviewed the manuscript.

Acknowledgements - Kathryn Sartain, Dr. Anne Garry, Dr. Michael Mawhinney, Dr. Sarah Butchard, Dr. Luna Centifanti, Hannah Sawyer, Dr. Steven Gilespie, my supportive partner, James, and friends, and family.

Ethical statement - Approval from the DClinPsychol Research Committee, University of Liverpool; the sponsorship review panel, University of Liverpool (sponsor ref: UoL001588), NHS HRA review board (IRAS ref: 289310), and the R\&D departments in each partner trust (North West ref: SP0564; North East ref: 289310). All methods were performed in accordance with the relevant guidelines and regulations. Consent from participants was explicitly obtained, recorded online, and held in a secure database.

\section{References}

1. Brown S. Why many doctors still find it difficult to talk about dying with patients. Canadian Medical Association Journal. 2019;191(1):E22-E3.

2. National Institute of Clinical Excellence (NICE). End of life care for adults: service delivery. NICE guideline. 2019;[NG142], UK.

3. Crawford G, Dzierżanowski T, Hauser K, Larkin P, Luque-Blanco A, Murphy I, et al. Care of the adult cancer patient at the end of life: ESMO Clinical Practice Guidelines. ESMO open. 2021;6(4).

4. General Medical Council. Outcomes for graduates: Practical skills and proceedures GMC, UK; 2020.

5. Nursing \& Midwifery Council. End of life care: Our position. NMC, UK; 2021.

6. Al-Samkari H. Striving for full disclosure-an intergenerational challenge. Cancer. 2020;126(6):1150-1.

7. Mack JW, Weeks JC, Wright AA, Block SD, Prigerson HG. End-of-life discussions, goal attainment, and distress at the end of life: predictors and outcomes of receipt of care consistent with preferences. Journal of Clinical Oncology. 2010;28(7):1203.

8. Morasso G, Caruso A, Belbusti V, Carucci T, Chiorri C, Clavarezza V, et al. Improving physicians' communication skills and reducing cancer patients' anxiety: a quasi-experimental study. Tumori Journal. 2015;101(1):131-7.

9. Wright AA, Zhang B, Ray A, Mack JW, Trice E, Balboni T, et al. Associations between end-of-life discussions, patient mental health, medical care near death, and caregiver bereavement adjustment. Jama. 2008;300(14):1665-73. 
10. Temel JS, Greer JA, El-Jawahri A, Pirl WF, Park ER, Jackson VA, et al. Effects of early integrated palliative care in patients with lung and GI cancer: a randomized clinical trial. Journal of Clinical Oncology. 2017;35(8):834.

11. Nipp R, El-Jawahri A, Temel J. Prolonged survival with palliative care-it is possible, but is it necessary? JAMA oncology. 2019;5(12):1693-4.

12. Draper EJ, Hillen MA, Moors M, Ket JC, van Laarhoven HW, Henselmans I. Relationship between physicians' death anxiety and medical communication and decision-making: a systematic review. Patient education and counseling. 2019;102(2):266-74.

13. Temel JS, Sloan J, Zemla T, Greer JA, Jackson VA, El-Jawahri A, et al. Multisite, randomized trial of early integrated palliative and oncology care in patients with advanced lung and gastrointestinal cancer: Alliance A221303. Journal of palliative medicine. 2020;23(7):922-9.

14. Weeks JC, Catalano PJ, Cronin A, Finkelman MD, Mack JW, Keating NL, et al. Patients' expectations about effects of chemotherapy for advanced cancer. New England Journal of Medicine. 2012;367(17):1616-25.

15. Whitehead PR. The lived experience of physicians dealing with patient death. BMJ supportive \& palliative care. 2012;4(3):271-6.

16. Zambrano SC, Chur-Hansen A, Crawford B. On the emotional connection of medical specialists dealing with death and dying: a qualitative study of oncologists, surgeons, intensive care specialists and palliative medicine specialists. BMJ Supportive \& Palliative Care. 2012;2(3):270-5.

17. Litvina D, Novkunskaya A, Temkina A. Multiple vulnerabilities in medical settings: invisible suffering of doctors. Societies. 2020;10(1):5.

18. Corradi MLG, Duim E, Rodrigues CIS. Death and End of Life: Perceptions Throughout The Career About Death, Palliative Care, and Educational Process. Journal of palliative care. 2020:825859720923435.

19. Lenherr G, Meyer-Zehnder B, Kressig RW, Reiter-Theil S. To speak, or not to speak - do clinicians speak about dying and death with geriatric patients at the end of life? Swiss medical weekly. 2012;142:w13563

20. Prod'homme C, Jacquemin D, Touzet L, Aubry R, Daneault S, Knoops L. Barriers to end-of-life discussions among hematologists: A qualitative study. Palliative medicine. 2018;32(5):1021-9.

21. Donnelly S, Walker S. Enabling first and second year doctors to negotiate ethical challenges in end-of-life care: a qualitative study. BMJ supportive \& palliative care. 2021.

22. Amati R, Hannawa AF. Relational dialectics theory: Disentangling physician-perceived tensions of end-of-life communication. Health communication. 2014;29(10):962-73.

23. Horlait M, Chambaere K, Pardon K, Deliens L, Van Belle S. What are the barriers faced by medical oncologists in initiating discussion of palliative care? A qualitative study in Flanders, Belgium. Supportive care in cancer : official journal of the Multinational Association of Supportive Care in Cancer. 2016;24(9):3873-81.

24. St Ledger U, Reid J, Begley A, Dodek P, McAuley DF, Prior L, et al. Moral distress in end-of-life decisions: A qualitative study of intensive care physicians. Journal of critical care. 2021;62:185-9.

25. French C, Greenauer N, Mello C. A Multifactorial Approach to Predicting Death Anxiety: Assessing the Role of Religiosity, Susceptibility to Mortality Cues, and Individual Differences. Journal of Social Work in End-of-Life \& Palliative Care. 2017;13(2-3):151-72.

26. Black K. Health Care Professionals' Death Attitudes, Experiences, and Advance Directive Communication Behavior. Death Studies. 2007;31(6):563-72.

27. Neumann M, Edelhäuser F, Tauschel D, Fischer MR, Wirtz M, Woopen C, et al. Empathy decline and its reasons: a systematic review of studies with medical students and residents. Academic medicine. 2011;86(8):996-1009.

28. Rodenbach RA, Rodenbach KE, Tejani MA, Epstein RM. Relationships between personal attitudes about death and communication with terminally ill patients: How oncology clinicians grapple with mortality. Patient education and counseling. 2016;99(3):356-63.

29. El-Rouby D, McNaughton N, Piquette D. Painting a Rational Picture During Highly Emotional End-of-Life Discussions: a Qualitative Study of Internal Medicine Trainees and Faculty. Journal of general internal medicine. 2020;35(4):1167-74.

30. Lang PJ, Davis M, Öhman A. Fear and anxiety: animal models and human cognitive psychophysiology. Journal of affective disorders. 2000;61(3):137-59.

31. Hojat M, Mangione S, Nasca TJ, Rattner S, Erdmann JB, Gonnella JS, et al. An empirical study of decline in empathy in medical school. Medical education. 2004;38(9):934-41.

32. Liu W-M, Forbat L, Anderson K. Death of a close friend: Short and long-term impacts on physical, psychological and social well-being. PloS one. 2019;14(4):e0214838.

33. Routledge C, Ostafin B, Juhl J, Sedikides C, Cathey C, Liao J. Adjusting to death: the effects of mortality salience and self-esteem on psychological wellbeing, growth motivation, and maladaptive behavior. Journal of personality and social psychology. 2010;99(6):897.

34. Figley CR, Bride BE, Mazza N. Death and trauma: The traumatology of grieving: Taylor \& Francis; 1997.

35. Bouri M, Papadatou D, Koukoutsakis P, Bitsakou P, Kafetzis D. The Impact of Pediatric Palliative Care Training on the Death Attitudes of Health Professionals. International Journal of Caring Sciences. 2017;10(2).

36. Prod'homme C, Jacquemin D, Touzet L, Aubry R, Daneault S, Knoops L. Barriers to end-of-life discussions among hematologists: A qualitative study. Palliative medicine. 2018;32(5):1021-9.

37. De Vries AMM, Gholamrezaee MM, Verdonck-de Leeuw IM, de Roten Y, Despland JN, Stiefel F, et al. Physicians' emotion regulation during communication with advanced cancer patients. Psycho-Oncology. 2018;27(3):929-36.

38. Kent B, Anderson NE, Owens RG. Nurses' early experiences with patient death: The results of an on-line survey of Registered Nurses in New Zealand. International journal of nursing studies. 2012;49(10):1255-65.

39. McKenzie EL, Brown PM, Mak AS, Chamberlain P. 'Old and ill': death anxiety and coping strategies influencing health professionals' well-being and dementia care. Aging \& mental health. 2017;21(6):634-41. 
40. Jackson C. Fear of failure. Understanding Learning and Motivation in Youth: Routledge; 2017. p. 30-9.

41. Ng L, Jenkins AS. Motivated but not starting: how fear of failure impacts entrepreneurial intentions. Small Enterprise Research. 2018;25(2):152-67.

42. Correia ME, Rosado A. Fear of failure and anxiety in sport. Análise Psicológica. 2018;36(1):75-86.

43. Costello J. Dying well: nurses' experiences of 'good and bad'deaths in hospital. Journal of advanced nursing. 2006;54(5):594-601.

44. White M. Saying hullo again: The incorporation of the lost relationship in the resolution of grief. Dulwich Centre Newsletter. 1988;3:29-36.

45. Atkinson JW. Motivational determinants of risk-taking behavior. Psychological review. 1957;64(6p1):359.

46. Conroy DE. Fear of failure: An exemplar for social development research in sport. Quest. 2001;53(2):165-83.

47. Thiemann P, Quince T, Barclay M, Benson J, Brimicombe J, Wood D, et al. 20 Negative personal emotional impact of caring for the dying-expectations of future doctors. a multicentre study. BMJ Supportive \& Palliative Care. 2018;8:A8.

48. Crowe S, Brugha R. "We've all had patients who've died...": Narratives of emotion and ideals of competence among junior doctors. Social Science \& Medicine. 2018;215:152-9.

49. Conroy DE, Elliot AJ. Fear of failure and achievement goals in sport: Addressing the issue of the chicken and the egg. Anxiety, Stress \& Coping. 2004;17(3):271-85.

50. Wolfreys J. Beyond 'Breaking Bad News': clinicians' experiences of disclosing a life-limiting illness to their patients. NZ: University of Canterbury; 2016.

51. Crowe S, Clarke N, Brugha R. 'You do not cross them': Hierarchy and emotion in doctors' narratives of power relations in specialist training. Social Science \& Medicine. 2017;186:70-7.

52. Economos G, Bonneville-Levard A, Djebari I, Van Thuynes K, Tricou C, Perceau-Chambard É, et al. Palliative care from the perspective of cancer physicians: a qualitative semistructured interviews study. BMJ supportive \& palliative care. 2020.

53. Crawford GB, Zambrano SC. Junior doctors' views of how their undergraduate clinical electives in palliative care influenced their current practice of medicine. Academic medicine : journal of the Association of American Medical Colleges. 2015;90(3):338-44.

54. Sagar SS, Lavallee D, Spray CM. Why young elite athletes fear failure: Consequences of failure. Journal of sports sciences. 2007;25(11):1171-84.

55. Sagar SS, Lavallee D, Spray CM. Coping with the effects of fear of failure: A preliminary investigation of young elite athletes. Journal of Clinical Sport Psychology. 2009;3(1):73-98.

56. Conroy DE, Willow JP, Metzler JN. Multidimensional Fear of Failure Measurement: The Performance Failure Appraisal Inventory. Journal of Applied Sport Psychology. 2002;14(2):76-90.

57. Faul F, Erdfelder E, Lang A-G, Buchner A. G* Power 3: A flexible statistical power analysis program for the social, behavioral, and biomedical sciences. Behavior research methods. 2007;39(2):175-91.

58. Sagar SS, Stoeber J. Perfectionism, fear of failure, and affective responses to success and failure: The central role of fear of experiencing shame and embarrassment. Journal of Sport and Exercise Psychology. 2009;31(5):602-27.

59. Álvarez-del-Río A, Marván ML, Santillán-Doherty P, Delgadillo S, Oñate-Ocaña LF. Facing death in clinical practice: A view from physicians in Mexico. Archives of medical research. 2013;44(5):394-400.

60. Mason S, Ellershaw J. Assessing undergraduate palliative care education: validity and reliability of two scales examining perceived efficacy and outcome expectancies in palliative care. Medical education. 2004;38(10):1103-10.

61. Merrill J, Lorimor R, Thornby J, Woods A. Caring for terminally ill persons: comparative analysis of attitudes (thanatophobia) of practicing physicians, student nurses, and medical students. Psychological reports. 1998;83(1):123-8.

62. Trizano-Hermosilla I, Alvarado JM. Best alternatives to Cronbach's alpha reliability in realistic conditions: congeneric and asymmetrical measurements. Frontiers in psychology. 2016;7:769.

63. The Jamovi Project (Version 1.6). Retrieved from: https://www.jamovi.org. 2021.

64. Zhang H, Carr ER, Garcia-Williams AG, Siegelman AE, Berke D, Niles-Carnes LV, et al. Shame and depressive symptoms: Self-compassion and contingent self-worth as mediators? Journal of clinical psychology in medical settings. 2018;25(4):408-19.

65. Biskup E, Vetter M, Wedding U. Fighting diagnostic and therapeutic nihilism in the elderly with cancer. Ann Palliat Med. 2019.

66. Sawyer JM, Higgs P, Porter JD, Sampson EL. New public health approaches to palliative care, a brave new horizon or an impractical ideal? An Integrative literature review with thematic synthesis. Palliative Care and Social Practice. 2021;15:26323524211032984.

67. Nordenskjöld S, Ågård A, Kock Redfors M, Naredi S, Block L. Swedish intensivists' experiences and attitudes regarding end-of-life decisions. Acta Anaesthesiologica Scandinavica. 2020;64(5):656-62.

68. Flanagan E, Chadwick R, Goodrich J, Ford C, Wickens R. Reflection for all healthcare staff: a national evaluation of Schwartz rounds. Journal of interprofessional care. 2020;34(1):140-2.

69. Amati, Hannawa AF. Relational Dialectics Theory: Disentangling Physician-Perceived Tensions of End-of-Life Communication. Health Communication. 2014;29(10):962-73.

\section{Table}

Table 2 is available in the Supplemental Files section.

\section{Figures}




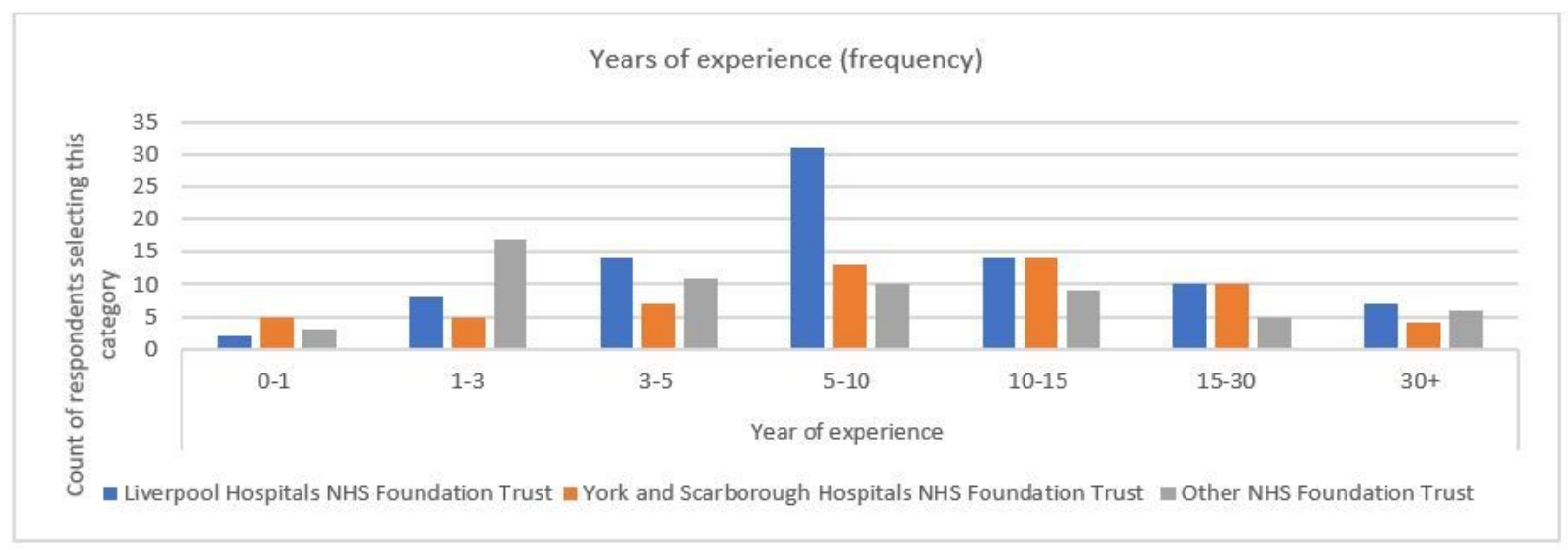

Figure 1

Clinician range of experience by trust

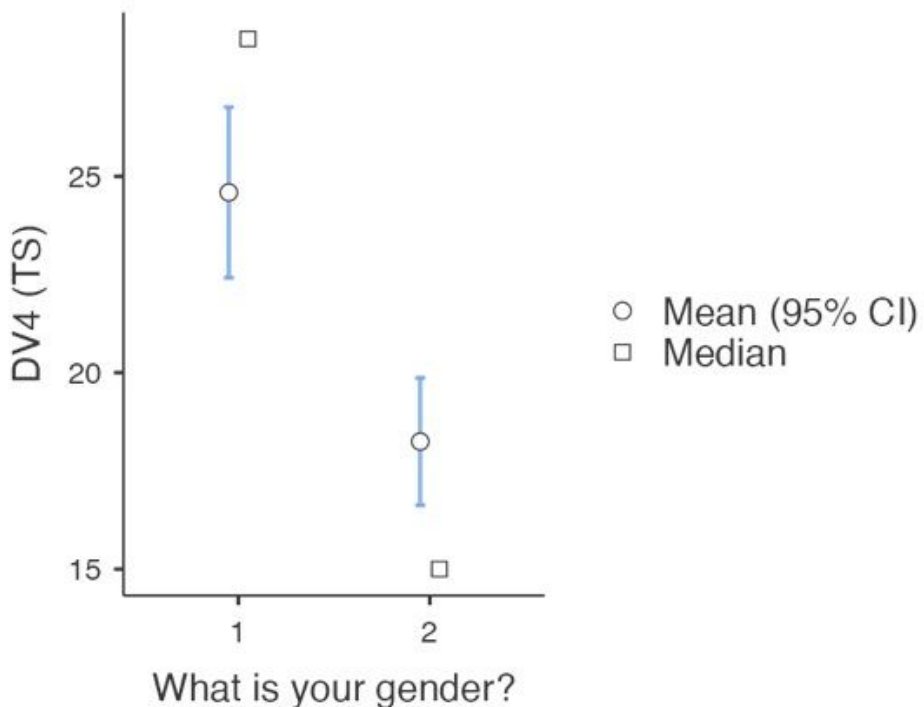

Figure 2

Mann-Whitney U comparison of male (1) and female (2) Thanatophobia scores

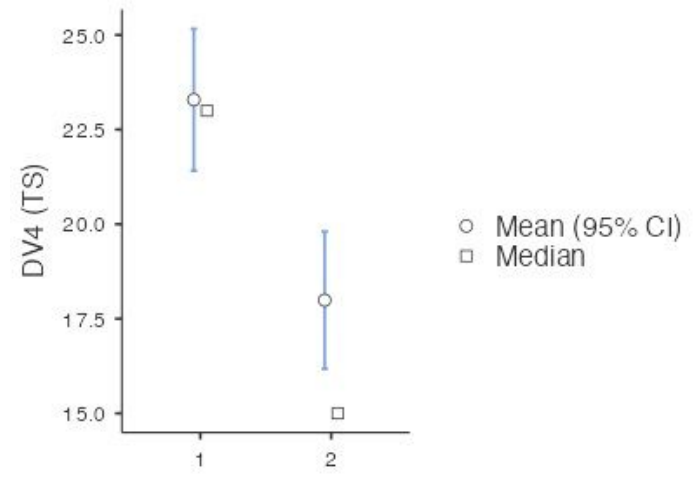

What is your role? - Selected Choice

Figure 3

Mann-Whitney U comparison of doctors (1) and nurses (2) Thanatophobia score 


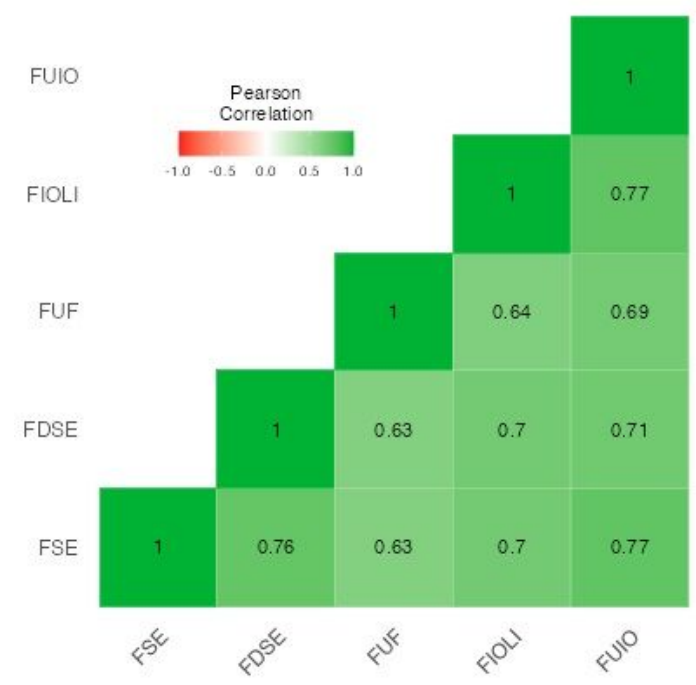

Figure 4

Correlation heatmap for 5 subscales of PFAl

\section{Supplementary Files}

This is a list of supplementary files associated with this preprint. Click to download.

- Table2.docx

- DataforsupplimentarypublicationfileV2BMCMar22.xIsx 